\title{
Research on the Present Situation and Countermeasures of Teaching Quality of International Volunteer Tourism Project in Mabul Island
}

\author{
Qianhan Xia ${ }^{1}$, Xinming Han ${ }^{2}$ \\ ${ }^{1}$ Institute of Education, University College London, London, UK \\ ${ }^{2}$ University of Science and Technology of China, Hefei, China \\ Email: hxm6025@mail.ustc.edu.cn, ier roy@foxmail.com, 107792689@qq.com
}

How to cite this paper: Xia, Q.H. and Han, X.M. (2019) Research on the Present Situation and Countermeasures of Teaching Quality of International Volunteer Tourism Project in Mabul Island. Open Journal of Social Sciences, 7, 254-264.

https://doi.org/10.4236/jss.2019.711018

Received: October 29, 2019

Accepted: November 22, 2019

Published: November 25, 2019

Copyright $\odot 2019$ by author(s) and Scientific Research Publishing Inc. This work is licensed under the Creative Commons Attribution International License (CC BY 4.0).

http://creativecommons.org/licenses/by/4.0/

\begin{abstract}
"International Volunteer Tourism" was born in Europe and America in 1920. It has a history of nearly 100 years, which experienced a rich evolution from simple initial scale to gradual maturity and internationalization. While vigorously promoting the development of education in poverty areas, world cultural exchanges, as well as world peace, the problem of International Volunteer Tourism has emerged, including high mobility of volunteers and instable local teaching quality. The author stayed in Malaysia for a week in charging of volunteer work, and researched by field investigation and described the severe living conditions and poor education of local students in Mabul Island. There are some problems in the development of international volunteers in Mabul Island, such as the high mobility of volunteers, incoherent teaching contents, and uneven teaching level. By analyzing the reasons and exploring solutions, the author puts forward three suggestions. First, strengthen publicity, combine government coercion and incentive policies. Second, advocate UNESCO to set up a unified teaching material and teaching plan for international volunteers worldwide. Third, encourage UNESCO and people who support the volunteer organization to set up foundations to relieve the financial pressure, as well as improving the quality of teaching in underdeveloped areas.
\end{abstract}

\section{Keywords}

International Volunteer Tourism, Mobility, Teaching Quality, Improvement

\section{Introduction}

"International Volunteer Tourism" originated in Europe and the United States 
around 1920, initially organized in France and Germany. After World War I, countries which experienced war and chaos were in urgent need of reconstruction. International work camps appeared at the right time [1]. While speeding up the efficiency of national rebuilding, they promoted world peace, cultural exchange, and social progress by sending volunteers to each other. Since then, International Volunteer Tourism has developed rapidly in Western countries. According to statistics, there are about 16 million people who take part in volunteer travel each year. Today, an increasing number of states join the international community, which is interdependent and cooperative. The relations between countries are harmonious, so as cooperation in economy and education. At present, volunteer tourism projects are transmitting to a more international, legalized, and advanced mode. Organizations in this filed are growing and diversified. Volunteers now can choose not only to teach locally but also to join other activities, such as feeding giant pandas, protecting sea turtles, cleaning coral reefs, and helping women with disabilities.

International volunteer tourism, known as public welfare tourism, is a tourist trip that aims at assisting economically underdeveloped countries and regions. By voluntary education, animal conservation, environmental protection, community building, and cultural exchanges, volunteers dedicate themselves to helping others [2].

In 2009, "International Volunteer Tourism" gradually emerged in China's coastal areas and attracted participants from college. Most of their motivation is self-demand-centered, which is influenced by self-interest and altruism. For example, volunteers arrive at the local area, integrating the volunteer teaching into the local life. They can get a first-hand experience about the living conditions in deprived areas, and understand the culture and history of foreign countries.

"Teaching Volunteer" is an important promoter and guide for the development of local education. They bring with general knowledge and excellent teaching ideas from all over the world to promote cultural exchanges, improve the quality of teaching, and raise global awareness of local poverty.

Currently, there are two types of "international volunteer tourism" volunteers in China. The first type is volunteers recruited through official channels, and the second type is volunteers organized by commercial or other non-profit organizations. The essential difference between the two is that one is wholly or partially covered by the agency, while the other is entirely at its own expense. International volunteer programs are located in impoverished areas in developing countries, where local people are struggling to survive, let alone provide better conditions for volunteers. That is a significant burden for the project, which is contrary to the original intention of international volunteers. Therefore, the number of volunteers in official organizations is minimal, and volunteers must meet higher requirements for professional knowledge, teaching skills, and life skills. On the contrary, volunteers who go at their own expense have relatively 
low requirements. Therefore, the teaching level of international volunteers is uneven. Most of the self-funded volunteers do not have rich teaching experience and skills, which limits the quality of the teaching process.

At present, the world's large-scale international volunteer organizations, including VSO, Helpx, Greenway, and Gapper, have set up educational volunteer programs [3]. Those programs occupy a vast market. According to a report published by the Association for Tourism and Leisure Education in 2008, the market now caters for 1.6 million volunteer tourists a year, with a monetary value between $£ 832 \mathrm{~m}$ and $£ 1.3 \mathrm{bn}$ [4].

The author took part in the teaching project of Gapper's school in Malaysia. During the project, the author conducted a one-week field study by interviewing 20 local volunteers, 3 local staffs, 20 students, 5 schoolmasters and teachers. The author obtained related data about Mabul Island from the head of Gapper. Finally, the author draws conclusions and proposes solutions from what the author have learned.

\section{The Current Living and Educational Conditions in Mabul Island, Malaysia}

\subsection{Residents on Mabul Island}

Located in Semporna, Malaysia, Mabul Island is a raised island between the Philippines and East Malaysia. Two thousand people live on the island, suffering a massive gap between the rich and the poor. There are three resorts in the island, at the resort, outer water is ideal for snorkeling and other leisure activities. It contains one of the world's top long-distance snorkeling spots, which is 15 minutes away from the diving resort island of Sipadan. Compared with the resort, the conditions in the slum are incredibly harsh-there's no fresh water or continuous electricity there, and full of dilapidated wooden houses. The island has no freshwater resources-residents can only use the desalinated seawater to wash rinses and take showers except drinking water. The author can peel off a thick layer of crystal salt on the face every time after I washed my face. With an inadequate power supply system, the island cannot guarantee a 24-hour uninterrupted power supply. Electricity only supply between 12:00 pm to 1:00 am, and 5:00 pm to 8:00 am. Residents can exclusively rely on natural light to living at the rest of the time. Life on the isolated Mabul Island, a 40-minute boat ride from Semporna in the middle of the ocean, is insular. The inhabitants of the island live entirely on the sea and fish, which makes life extremely difficult. Apart from the lack of fresh water and sustainable electricity, it is also challenging to purchase daily necessities and food. For residents, the island's old commissaries and craft stores are regard as luxury items, mostly available to tourists. Walking on the island, well-dressed residents are rare, and most residents are dressed in rags, walking barefoot, and many children even naked. Besides, the slums are the home to the world's only stateless people, the Bajau people. Slums are known as 
"the last sea Gypsies", who lives in the sea and rarely land for generations.

\subsection{The Present Situation and Problems of Education in Mabul Island}

There are only three primary schools on the island, one government primary (around 120 students) and two non-government primaries (around 100 students). The participation rates in schools are almost the same near $90 \%$.

The local government runs the government primary school with regular teachers, rigorous teaching programs, textbooks, and a well-equipped campus. Non-government primary schools belong to a local private owner. One of them is designed to assist its employees to take care of their children during their work time. The school was built with a wooden shack, which contains a kindergarten and the first and second grades. The other non-government school offers classes only at night and focuses on religious knowledge, so international volunteer volunteers are rarely invited. Since it is running by a private owner, teachers in the school are non-professional and voluntary, who are the staff of the owner's shop. Teachers are free to choose to attend classes every day. Besides, the school has neither fixed textbooks nor strict teaching plans.

Local students are divided into two categories. The first type of students is local citizens holding Malaysian identity cards. They can attend government primary schools, complete local studies, and get higher education. Other students are stateless, including undocumented refugees from Bajau people and other countries, migrated to Mabul Island because of war or other reasons. They are temporarily accepted by Malaysia but had no identity cards. Such students can only go to non-government primary schools until the end of the second grade and then no longer have any access to education.

This paper summarizes the problems of education in Mabul Island. The author used field surveys and interviews to demonstrate those problems, which are based on volunteer teaching experience in government primary schools and non-government primary schools during the daytime.

\section{1) Lack of Educational Resources}

There are only primary schools on Mabul Island, where no secondary schools have been biult. Students who are enrolled in government-run primary schools can only go to secondary schools in Semporna or adjacent islands if they wish to continue their studies after graduation. Bong Bong Island, an hour's boat ride from the small town of Semporna, is also an isolated island. Having high-school education means leaving Mabul Island and their families. Most students would not choose to go for higher education. The extreme scarcity of educational resources on the island leads to a narrow range of knowledge available to students. This situation cannot be promoted because of the island's closed and restrictive development policies. To a large extent, it has limited the development of local education.

There are only two grades in non-government schools, which are exclusively designed to teach students fundamental skills such as reading and writing. 
Students cannot develop good study habits there. After graduating from a non-government school, some stateless students will return to the sea to fish and sell seafood. Others may go to work in restaurants in Semporna, where they are barred from attending school for the rest of life. If they were later given an identity card, they could also re-enter government schools, yet the general stateless population would not choose to continue their studies. The paucity of educational resources prevents stateless students from pursuing higher education throughout their lives. It also restrains students from gaining complete knowledge in just two years of schooling.

\section{2) Low Teaching Quality}

While government primary schools have qualified teachers, non-government primary schools also have teachers. Those teachers have lower education background and teaching ability. The local teachers in Mabul Island are all native-born residents, and the quality of their education is deficient. They teach superficial knowledge to future generations, or even showing wrong knowledge points. For example, when we went to a non-government primary school, the teacher was teaching the singular and plural forms of English words. We all know that English word for a woman is woman, pronounced as ['womən], and the plural form of this word is women, pronounced as ['wimin]. There is an obvious different pronunciation between the two, but the teacher tells the students that the two words sound the same.

Non-governmental primary schools do not have standard teaching materials and teaching plans. Teaching activities are chaotic there. Besides, the content and the time of classes are uncertain. Time is scarce to form a complete knowledge system for students. The teachers' level is not high; the knowledge transmission is wrong; the teaching quality is low. Education development is limited there. Thus, international volunteers are needed to carry out education assistance to help improve the local backward education status quo and to enhance the quality of teaching to a certain extent.

\section{Problems in Educational Assistance by International Volunteers in the Mabul Island}

The international teaching volunteer program on Mabul Island is still in the process of maturing and improving after its launch in May 2018. The quality of teaching cannot be guaranteed in the beginning. All teaching activities on the island are in partnership with the Gapper Volunteer Organization only. The world ignores this program. The poor conditions on the island make it impossible to provide better living conditions for volunteer teaching staff and for good teachers to carry out long-term local teaching activities.

The above three points are common problems in the quality of international volunteer projects. In recent years, the destinations of teaching volunteer projects all over the world are located in deprived areas. Poor economic conditions, shortage of teaching resources, and poor living environments make international aid for education more difficult. Through communication with local educators 
and project leaders, the author summarized the problems of international teaching volunteers on Mabul Island. Through the research on personality and literature of Mabul Island teaching volunteers, the author found existing common issues in the International Volunteer Tourism Teaching Program.

\subsection{Short Working-Hours and High Mobility of Volunteers on Mabul Island}

The government primary school in Mabul Island has two grades reserved for international volunteer volunteers. There are no fixed curriculums or teaching plans. Non-governmental primary schools have no regular teachers and recruit international volunteers for a long time. The limitations of international volunteer mobility have manifested the length of volunteer activities. And their teaching knowledge is also limited. Volunteers can choose their working time, varies from one, two, to three weeks. According to the relevant data obtained from the Gapper leaders, the total number of participants in Mabul Island volunteer program is 254 since May 2018. The total number of participants who have been working for one week is 238 , accounting for $93.7 \%$. Fifteen participants have been working for two weeks, accounting for about 5 percent. Less than 1 percent of participants have been working for three weeks.

At the same time, this article conducted interviews with 20 local volunteers who participated in the project, including Chinese, Koreans, and Japanese. When asked what effect their choice about the working-time, most students chose a week because they just wanted to experience life, rather than dedicated to teaching activities. Secondly, the local living conditions are backward, and the living conditions were poor. Few volunteers are willing to stay in the area for long periods. So the maximum volunteer time so far is only 3 weeks, which only one student had chosen. The international volunteer mobility of Mabul Island is high, and the teaching time is short. These problems in teaching are apparent.

\subsection{Incoherent Teaching Contents}

To obtain more teaching information, the author communicated with other volunteers from South Korea by e-mail. Through the exchange of information, the author found that volunteers from different countries and regions will teach according to their understanding and culture. There is no unified teaching materials and teaching programs on Mabul Island. For example, Korean volunteers will teach pure Korean. China volunteers will teach basic Chinese, such as "Ni Hao" and "XieXie", in a limited time. According to the exchange with the school principal, the school has received large numbers of Japanese volunteers before, and local students have also learned basic Japanese. It shows that the content of volunteer teaching is very different, and a unified teaching system has not yet formed. There is no opportunity to communicate with the volunteers teaching content. 


\subsection{Varies Teaching Standard}

This project has both experienced teachers of Chinese as a foreign language professional graduate students and non-education professional college students. Some teachers come from high school with non-teaching experience. In a week of teaching activities, we clearly observed that graduate students with rich expert knowledge are good at putting classroom theory into practice. They have strong classroom motivation, relatively teaching skills and solid teaching knowledge, and good at communication with students in the classroom. They know how to use various teaching methods to show teaching knowledge points. For example, when a teacher wanted to teach Chinese sentence such as "good morning", "good afternoon" and "good evening", she would use situational teaching method to interact with the students, setting up different situations and asking them to say hello with each other in Chinese. She not only aroused students' interest but also enriched the classroom teaching atmosphere. Instead, we observe that high school students with no teaching experience are very rusty and passive in their education [5]. For example, when he tried to tell the story about The Tortoise and the Hare, he told the story to the students as it was, without using other teaching methods, or interacting with the students. The class ended in a dull classroom atmosphere, students' inattention, and other problems. After class, we interviewed the students and asked them which teacher's teaching method they preferred. According to the survey of the 35 students in a class, 32 preferred the "graduate teacher's" class, accounting for $91 \%$ of the course. Three other students said they liked the "high school teacher's" approach. In the next day's class, the volunteers reviewed the lessons from the previous day, and found that the students still remembered what the "graduate teacher" had taught, while completely forgot what the "high school teacher" had told. It shows that teachers with rich teaching experience are more effective than teachers without teaching experience. The teaching level of volunteers is uneven; the knowledge that students can receive is limited, and the teaching quality cannot be improved. There are considerable limitations in international volunteering education [6].

To sum up, the volunteers come from all over the world. There is no fixed teaching material and teaching plan for the volunteer projects. They all teach according to the customs and languages of their respective countries. The teaching content is confused, and the system is not perfect because the students do not have systemetic teaching. According to the survey, the same problem exists in the Nepal volunteer program. The investigator went to an orphanage in Bockara for volunteer teaching [7]. It takes seven hours to get there. She was the only one to volunteer for the two-week program. The current problems of international volunteer work are the limited time, high mobility, lack of teaching resources, and low quality of teaching, which cannot solve the local teaching problems at all. The living environment of volunteer volunteers is poor, and most of them go at their own expense. The issue of money and living environment has become an essential factor in attracting excellent teachers. The teach- 
ing content is confused, and the teaching progress cannot be linked up. There are many limitations to international volunteer teaching. Under the circumstances of international volunteer mobility, how to improve the local teaching quality is an urgent problem.

\section{The Countermeasures and Suggestions for Improving the Teaching Quality of International Volunteers in Mabul Island}

International volunteer tourism has developed rapidly in recent years, attracting a large number of volunteers to participate. However, most of the literature focuses on the impact and promotion of volunteer travel on volunteers themselves, and very few studies have focused on the quality of volunteer teaching. In this paper, through literature research and field research, the author combined with the actual situation of Mabul Island, and made the following suggestions to improve the local teaching quality of Mabul Island.

\subsection{Strengthen Propaganda, Government Coercion and Incentive Coexist}

It is significant to strengthen the promotion of international volunteer work worldwide so that more people will understand the true meaning of international volunteer work and volunteer education, pay more attention to the teaching poor areas in need of help, and advocate the whole society to help those in need. It is also essential to improve the quality of the population to contribute to the peace of humanity. In order to promote volunteer tourism, some countries have linked volunteer public welfare activities to the immediate interests of national citizens, such as their success in employment. They also promote educational significance and enhance social response. For example, 50 percent of the population of Japan has participated in volunteer activities. The government of Thailand has promoted volunteerism, required university graduates to volunteer in poor areas for one year, after which they will have a better chance of getting a good job upon graduation. French law requires their citizens over the age of 18 to perform voluntary national service, and offenders are sentenced to two years in prison, of which the Civil Service is overseas volunteer, travel to assistance. In America, people who join the one-year "volunteer for America" program, and complete with a two-semester, will get a fellowship of $\$ 9450$ and more [8]. It shows that in developed countries, the concept of international volunteer has become quite popular, and states have taken relevant measures to promote the development of volunteer services. This is also an effective measure to ensure the volunteer time. The long time of volunteers ensures the teaching quality to some extent.

In contrast, the late introduction of developing countries on propaganda work is relatively backward. In terms of Southeast Asian countries, national citizens are more focused on "volunteer" rather than "do volunteer", national conditions lead to the limited number of volunteers. In China, for example, since the intro- 
duction of international volunteers in 2009, the concept and promotion of international volunteers have only been developed in the eastern coastal areas, the inland areas are still lack of promotion. Therefore, the author urges developing countries to follow the trend of international volunteer development. The Ministry of Education should strengthen the promotion of volunteer education. We can combine international volunteer activities with National Basic Education to promote the overall quality of our citizens. We need to improve the teaching capacity of volunteers, improve the quality of international volunteer teaching, so that leads to the development of international education, modernization.

\subsection{Standardize Teaching Material and Unify Teaching Plan}

United Nations Educational, Scientific, and Cultural Organization calls for standardized teaching materials and programs worldwide or in relatively concentrated areas. In areas where more mature programs have been formed, international volunteer volunteers can "teach students by their aptitude" according to the unified teaching materials and local conditions to create a complete teaching system and improve the consistency and cohesion of the course contents to solve the knowledge gap problem. Areas that have been identified and given volunteer help are lucky enough to be relatively unwatched, even though living conditions are still weak. At the same time, it is also a learning opportunity for volunteers who have no teaching experience and lesson plan. Under the leadership of international organizations, they can improve their teaching ability, enrich their teaching and life experience, which also benefits to the local people.

\subsection{Widely Raise Funds to Attract Excellent Teachers}

It is suggested that the United Nations Educational, Scientific and Cultural Organization and the people who support the volunteer cause should set up relevant foundations, committees, etc. They should give specific financial support to outstanding teachers who wish to participate in international volunteer work, and set up training courses, etc. At present, there are two types of international volunteers: those who are paid by the government and those who require volunteers to travel at their own expense. Official government dispatches are demand and limited, and most inexperienced volunteers have no choice but to opt for self-financed programs from public interest organizations and international organizations. As the name suggests, international volunteers are going to the world. Most of the volunteers will choose non-local areas to support their education. Besides the cost of the project, transportation and accommodation are also considerable expenses. According to the length of time to give a certain subsidy, we need to relief the financial pressure of international volunteer volunteers, to attract more excellent teachers, to improve the quality of volunteer teaching.

In financial help, we can divide different kinds and grades. In China, for example, we can divide the people who have been subsidized into teachers with teaching age of more than 20 years, more than 10 years and less than 10 years. The longer the teaching age is, the more financial support can be obtained, such 
as the highest amount can be 20,000 yuan, and the lowest amount is 2000 yuan. In addition, the selection of volunteer hours can also be used as a level standard. The longer the volunteer's time, the more funds they get.

\section{Conclusions and Limitations}

At present, from the perspective of the development of foreign volunteer tourism, it is developing towards the direction of legalization and nationalization [9]. Volunteer organizations are growing in size and diversity, and more and more of the world's poor are being found and helped. Meanwhile, the problems of volunteer mobility and teaching quality still remain dominant. The author hopes that the above three suggestions can, directly and indirectly, affect and enhance the quality of volunteer teaching activities and promote the healthy development of international volunteer education.

The study found that there are some limitations in the development of International Volunteer Tourism Program in Southeast Asian countries, such as the relatively short duration of Mabul Island volunteer program and the lack of available data due to cultural differences among volunteers. There may be some information errors in the interview process with foreign volunteers so that the conclusion may be one-sided [10]. Besides, the proposed countermeasures in this paper are relatively macro and need further in-depth study in operability.

\section{Conflicts of Interest}

The authors declare no conflicts of interest regarding the publication of this paper.

\section{References}

[1] Tian, Z.L., Bai, K. and Liu, C. (2019) Young Chinese People's Motivation to Participate in International Volunteer Tourism and Its Influencing Factors. Tropical Geography, 39, 420-429.

[2] Liu, H.Y., Gu, G.J. and Chen, M.Y. (2018) On the Cultural Expression of College Students' International Volunteer Tourism. Journal of Beijing City University, No. 4, 66-69.

[3] Smith, P. (2014) International Volunteer Tourism as (de) Commodified Moral Consumption. Bulletin of the American Mathematical Society, 80, 266-270.

[4] Butcher, J. and Smith, P. (2010) 'Making a Difference': Volunteer Tourism and Development. Tourism Recreation Research, 35, 27-36. https://doi.org/10.1080/02508281.2010.11081616

[5] Zhang, Q.Y. (2018) Intercultural Communication in International Travel by Chinese Youth-Take traveling Volunteer-Phuket Dengba International Youth Hostel For Example. Zhengzhou University, Zhengzhou.

[6] Alexander, Z. (2012) The Impact of a Volunteer Tourism Experience, in South Africa, on the Tourist: The Influence of Age, Gender, Project Type and Length of Stay. Tourism Management Perspectives, 4, 119-126. https://doi.org/10.1016/j.tmp.2012.07.002

[7] Zhang, C. (2015) Being an International Volunteer in Nepal. Extracurricular Read- 
ing, No. 12, 21-22.

[8] Mueller, S.L. and Overmann, M. (2008) Working World: Careers in International Education, Exchange, and Development.

[9] Lyons, K.D. and Wearing, S. (2007) Journeys of Discovery in Volunteer Tourism: International Case Study Perspectives. Journeys of Discovery in Volunteer Tourism International Case Study Perspectives, 4, 363-371.

https://doi.org/10.1079/9781845933807.0000

[10] EAA (2013) International Volunteer Tourism. 